\title{
Human Resource Management: Challenges And Strategies For Retaining Nurses At A Private University Hospital In Karachi, Pakistan
}

\author{
Rozina Karamaliani \\ School of Nursing and Midwifery and Community Health Sciences \\ Aga Khan University \\ Shirin Rahim \\ School of Nursing and Midwifery \\ Aga Khan University \\ Syed Aamir Hameed \\ Department of International Relations \\ University of Karachi
}

\begin{abstract}
Human resource for health, especially nurses, is the greatest challenge worldwide for most of the countries. This shortage has compelled hospital's management and leadership to identify its causes and strategize interventions to overcome the deficit in order to improve and sustain quality health care for patients. This paper identifies issues affecting nurses' retention and suggests recommendations for creating job enrichment and enhancing retention at a private university hospital in Karachi Pakistan. A contextual secondary data analysis of M.Sc. Nursing thesis, exit interviews and external evaluators' report (2004) of a private university hospital in Karachi Pakistan along with review national and international studies published during 2001- 2013 on the factors affecting and strategies to improve nurses' retention, attrition and job satisfaction. The contextual secondary analysis identifies the 5Ms including "management, migration, marriage, money and mother in law" to be the reasons of resignations identified among nurses. Whereas global literature highlighted two sets of reasons one is related to work life including higher education opportunities for career advancement, personal reasons, marriage, family commitment, and relocation for better prospects. The other set of reasons are work environment including overwork, lack of collegiality with co-workers, and lack of recognition from management. Moreover a model for nurses' retention was developed to suggest ways to protect health human capital investment in a private university hospital. With prevailing country security situation in Pakistan, high cost impact of retention, sponsorship and escalating overseas demand, turnover will continue to remain a constant challenge. Healthcare organizations are strongly advised to invest in talent management practices that will have the greatest value for ensuring a steady workforce of qualified and engaged nurses.
\end{abstract}


Keywords: Nurses' Job Retention, Job Satisfaction, Attrition, Health Human Resource, Nurses' Shortage

\section{تلخيص}

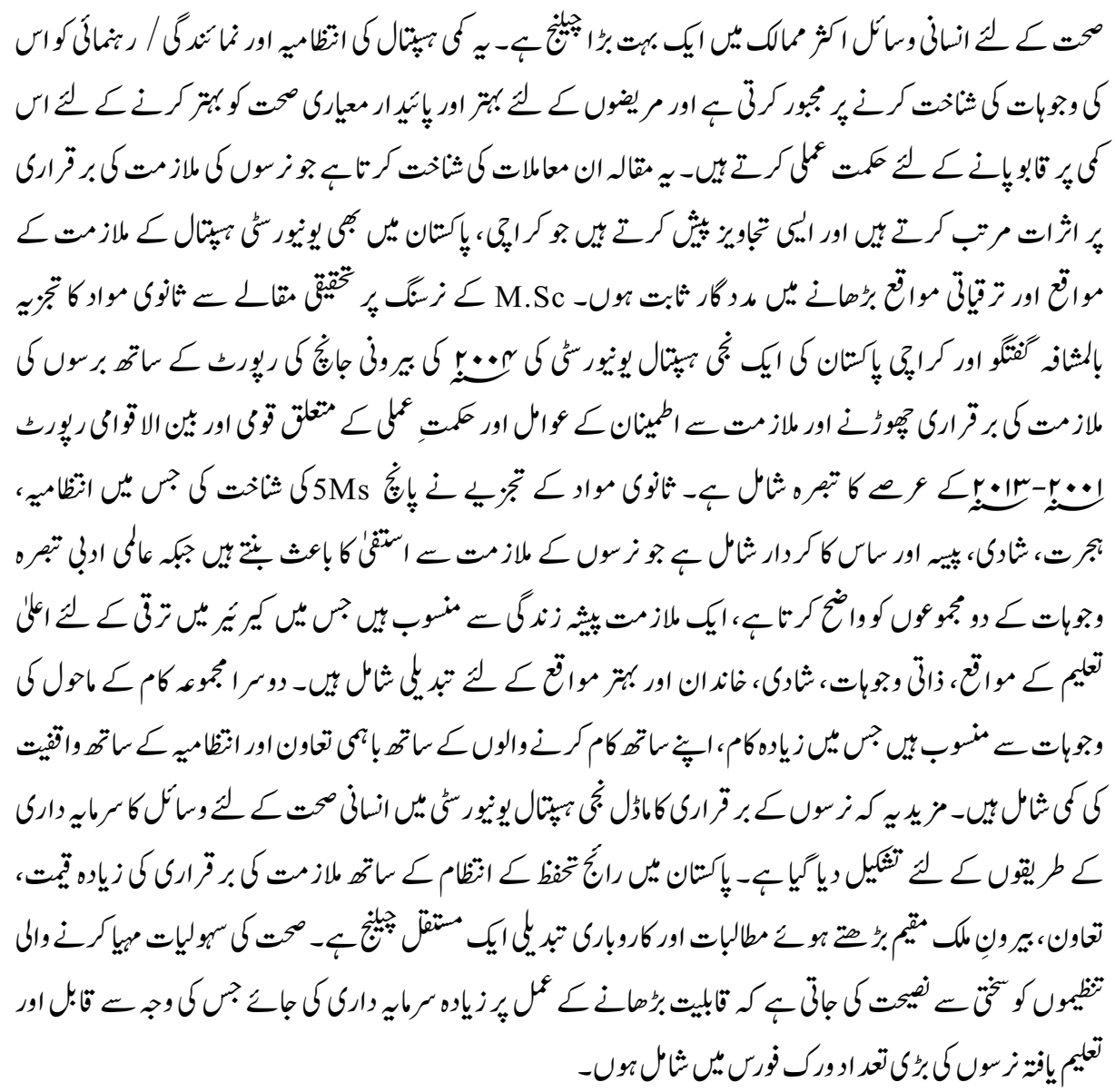

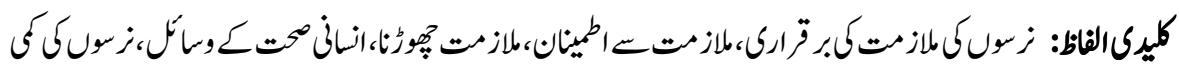

\section{Introduction}

Human resource for health (HRH) or health workers are 'all people engaged in actions whose primary intent is to enhance health' (The World Health Report, 2006). CastilloLaborde (2011) has categorized HRH in two distinct type health services providers (e.g. physicians, nurses, midwives, and laboratory technicians) as well as health management and support workers (e.g. accountants in a hospital, administrative professionals, and 
drivers). HRH is essential for the input, productivity, growth, and efficient functioning of health care systems of any country (Gupta \& Dal Poz., 2009; Castillo-Laborde, 2011).

An overwhelming number of countries are challenged by health worker scarcity, with estimated shortage of 4.3 million doctors, nurses, midwives, and support workers worldwide (The World Health Report 2006). This dearth of HRH is considered to be a global health crises (Chen, et al, 2004) forcing health systems to relook to their policies and strategies for human resource development, recruitment and retention without any delays. The most urgent agendas of today's health systems worldwide are not only attaining the appropriate number of HRH but also to work for their productivity and balanced geographical distribution according to skill mix, population need and quality of health services these HRH can provide ( Castillo-Laborde, 2011).

Nursing being one of the essential HRH is also facing the same issues of shortages in developed as well as developing countries around the world. International Council for Nurses (ICN) report on the global shortage of registered nurses attempted to highlight nurses' shortage and their uneven distribution worldwide by highlighting the nurse/ population ratio in different countries which is ranging from more than 1,000 nurses per 100,000 to less than 10 nurses per 100,000 populations (Buchan \& Calman, 2004).Throughout the United States, in the last five years there has been a 10 per cent vacancy rate for nursing positions (Sliby, 2003).In Australia, the same vacancy rate is as high as 60 percent for the registered nurses it needs (Dow, 2003).

The situation is not different in developing countries particularly in Pakistan which stand out as one of the 57 countries facing HRH shortage. There exists a shortage of 60,000 nurses (Khuwaja, 2013) having one trained nurse for the population of 3568 in the country (Iqbal, 2011; Khuwaja, 2013).

The lack of retention and the gap between the demand and supply of nurses, in developing countries is multi-factorial and includes several work life as well as work environmental reasons (Hunt, 2009) which make nurses dissatisfied with their job and hence nurses are compelled either to leave the profession or migrate to another country. According to the International Council of Nurses "thirty three countries - primarily from Oceania, Africa, Central America and the Caribbean - reported that the outflow of nurses to more affluent countries is a serious problem, worsening the shortage that already exists." Moreover, in countries like Pakistan, where cultural factors also influence women's career, nurses also leave their jobs because of marriage, pregnancies, 
and other domestic reasons making the scenario more worst (Khowaja, Merchant \& Hirani, 2005).

Inability, of government and stake holders to deal with nurses' shortage may results in poor health services and poor patients' and nurses' outcome. Around 70- 80\% of country's budget is allocated to deal with HRH management and hospital managements and the nursing related policy makers in Pakistan are now highly compelled to consider different strategies to overcome these reasons which are causing shortage of nurses' in the health system (Khuwaja, 2013).

This study presents one such endeavor of a private tertiary care hospital of Karachi Pakistan where the need was acknowledged to identify work life and work environment issues of nurses affecting their retention and review strategies to retain the nurses to balance the turnover.

\section{Methodology}

A contextual secondary data analysis of a private university hospital in Karachi Pakistan was conducted along with review of global literature. The contextual literature included 2 MSc Nursing theses (Jaffer, 2003; Lalani, 2005), exit interviews of nurses and the external survey report (2004). Whereas, national and international literature include 8 studies on the factors affecting nurses' retention, attrition and job satisfaction, published during 2001-2013. Various data bases such as Google Scholar, PUBMED and CINAHL were used to extract articles using the following keywords: nurses' retention, job satisfaction, attrition, health human resource, nurses' shortage

\section{Findings}

The contextual secondary data analysis presented 5Ms as reasons for nurses' lack of retention. These five Ms are management, migration marriage, money and mother in law as mentioned earlier.

Moreover the literature review identified several work life and work environment reasons affecting nurses' retention. The work life reasons of resignations identified among nurses are; higher education opportunities for career advancement and growth, marriage, family commitments, relocation for better prospects and lately law and order situation as nurses work on shifts and often required to either start or finish on the odd hours of the day. Whereas the work environment reasons revealed out of this study are extreme work load, 
lack of collegiality with doctors and co-workers, low control over job performance and lack of recognition from management.

Based on the factors identified in contextual and global literature, that affect nurses' retention, this study proposes Nurses Retention Model (figure 1) to help stakeholders strategize a way forward for retaining nurses at the private university hospital in Karachi Pakistan.

The focus of Nurses' Retention model is the key "strategic imperative" with special attention on strategies that enhance retention culture and eliminate those factors that do not- encourage and support nurses to stay. The four proposed areas of the model, namely Effective nursing leadership, effective career development opportunities, innovative compensation and benefit package, and effective rewards and recognition, are easily controllable by nursing management and can capture both the work life and the work environment factors of nurses' resignation from their services. Operational strategies employed in these proposed areas can yield positive results in enhancing nurses' job satisfaction and ultimately improving their retention.

Effective nurse leadership is the most important of all the four areas depicted in the model. An effective leader creates an effective working environment within which the employees demonstrate their efficiency and productivity. Under the leadership of an effective leader, employees also enjoy the work place and are remain willing to commit their long term loyalty and dedication for their work and organization. Few measures which an effective nurse leader may practice while dealing with staff nurses include maintaining connection emotionally with the team and build a strong emotional bank account, creating a shared vision of the unit as they want it to be, bringing clarity to the desired goal, guide people in their decision and inspire people to work toward this shared vision, identifying nurses in an organization with a solid foundation established work for "succession planning", identify nurses who may have the potential to become future leaders and train them to be effective leaders. (Clarin, 2007; Mrayyan, 2008; Rhay-Hung, et al., 2010; Steven, 2009; Verhaeghe, et al., 2008)

Provision of career development opportunities will enhance nurses' empowerment, selfconfidence, and self-reliance which will ultimately affect their retention within the health care system.

Provision of substantial monitory benefits may play critical role in nurses' family life where they often share the monetary burden and in some cases are the main bread earner in the family and in doing so they remain attached to their work places. Effective rewards 
and recognition will help nurses to maintain their respect and dignity within the work environment and boost their sense of self accomplishment which in turns enhances job satisfaction and improves retention.

\section{Discussion}

Nursing, probably, is the only profession other than doctors where the professional satisfaction has broader connotation. That is compassion satisfaction and job or professional satisfaction, both of them are not only interconnected but are also multidimensional, and both are highly vulnerable and dependent upon various factors. Some of these variables are institutional, societal, personal and family based.

This study revealed considerable work life and work environment reasons due to which nurses resign from their jobs. Several work life reasons (marriage, and family commitments) discovered by the study findings does not seem to be in control of nurses or nursing management to modify or work upon to have considerable impact on nurses' retention. However, some of them for example, higher education opportunities, opportunity to migrate and better prospects along with the work environment related reasons identified from this study are also "push" factors for the nursing management to a greater extend. Addressing and rectifying them will can yield positive results in enhancing nurses' retention. Moreover, other factors are inadequate resources, insufficient staffing, perceived lack of support, and poor working conditions were identified in studies done in Philippines which negatively affected Pilipino nurses' job satisfaction and their high turnover rate (The Philippine Star, 2015).

To enhance the understanding about modifying the identified issues of nurses turnover and enhancing nurses retention, A Nursing Work Life Model (Manojlovich, \& Laschinger, 2008) (Figure2) is used. This model in three steps augments the understanding of stakeholders to overcome job satisfaction issues particularly those related to work environment domain, in order to retain nurses for longer period of time. Effective nursing leadership is the hall mark of this model which significantly influences all the other factors of nurses' attrition and turnout.

Firstly, nursing leadership has its effects on nurses staffing, resource allocation and, resource adequacy all of which are directly related with the work load of nurses. The work load increases when nurses are expected to provide quality patient care in absence of adequate staffing resulting in turnout of nurses and one of the reasons for nurses to quit 
jobs prematurely. Effective nurses leader will allocate and relocate the human resource in such an efficient manner that the issues of work load can be taken care off.

Secondly leadership can positively affect the inter-professional collaboration of nurses, physicians and other professionals working in hospital settings. This collegiality facilitates emergence of conducive working environment where dignity and respect of all the health care providers is valued. Measures that a nurse leader may take to enhance inter-professional collaboration of nurses, physicians and other professionals including providing formal orientation to physicians on Nurses scope of practice and role, collaboration of medical students to graduate nursing students early in their educational career, holding all team members accountable for the improvement of professional communication, ensuring opportunities of interdisciplinary rounds with nurses to visibly show the patient/family the nurse's involvement with the medical management. (Clarin, 2007; Mrayyan, 2008; Rhay-Hung, et al., 2010; Steven, 2009; Verhaeghe, et al., 2008)

Thirdly effective leadership may enhance nurses' feelings of self-accomplishment and a sense of control over their jobs by providing positive reinforcement motivation and recognition to all the little contribution that y make to improve patient care.

Hence, according to Nursing Work Life Model (Manojlovich, \& Laschinger, 2008) almost all the work environmental factors affecting nurses' retention can be modified and controlled by providing effective nursing leadership. An effective nurse leader paves the way for effective work environment and enhances nurses job satisfaction and improves their retention. Hospitals, all over the world have started investing in positive work environment for nurses to help nurses improve job satisfaction and thereby increase their retention (Van den Heede et al., 2013).

Apart from effective nursing leadership, hospitals need to strategize in more innovative ways to address issues affecting nurses' retention. While there is so called no "silver bullet" solution that will create reductions in nursing turnover across the board, many solutions have been found to positively impact turnover. On the other hand, there is no "one size fits all" ideal job design. Any healthcare organizations that wish to maximize nurse retention must develop methods to provide nurses with flexibility to structure their job based on their own and often unique set of interests. This requires giving nurses a way to exert control over their schedules, access to career development opportunities for nurses who want them, and financial incentives that allow nurses to increase their compensation levels. 
The proposed "Nurses Retention Model", may provide an answer for several hospital managements as it did for a private university hospital at Karachi Pakistan. The university's academic and nursing service leadership with the support of Human Resource and Finance departments initiated to bridge the gap by improvising few retention strategies based on the proposed Nurses' Retention Model.

Following strategies are employed in the university considering all the identified factors in this study particularly the contextual ones. The strategies were proposed ensuring a balance between nurses work- life and work -environment domains, reducing nurses work load, providing substantial monitory benefits and opportunities for higher education.

1. Duty hours in morning and evening shifts are reduced from 9 hours to seven and half hours each. This measure was meant not only to take care of mother in law factor but also other routine responsibilities.

2. Work -study model through adopting blended learning approach at the university's School of Nursing and Midwifery was initiated to provide nurses opportunity to study and work at the same time.

3. Sponsorships and financial assistance loan program are kept open for nurses eager to opt for higher studies with service agreement. This measure aimed at providing nurses opportunity and flexibility to pay their tuition fees and other higher education expenses in more convenient manner

4. One year internship is kept mandatory for graduation requirement of newly graduate nurses on staff salary.

5. Shift differential allowance is introduced according to market salary adjustment to answer "Money" factor.

6. Job sharing; pro-rated out-patient medical benefit; subsidized transport and prorated earned leave for part time nurses are being introduced, again to satisfy Money factor.

It has been two years since these strategies were adopted at the university, resulting in improvements in terms of nurses' job satisfaction, improved work environment factors and increased nurses' enrolment in higher education program of the university is observed. However a comprehensive survey showing the impact of these strategies on nurses' retention is yet to be performed to ensure that these strategies have produced better nursing and patient care outcome. 


\section{Recommendations}

Healthcare organizations are strongly advised to leverage the results of this research to invest in talent management practices that will have the greatest value for ensuring a steady workforce of qualified and engaged nurses.

Following are the six components of talent management presented in Talent Management Strategies Research Report, 2012 which serve to be a source of recommendation for strengthening health human resources in health care organizations. Nursing leaders must know and utilize these components in practice to ensure enhanced job satisfaction and improved retention of their employees in terms of sustainability of human resources.

\section{Workforce Planning, Recruiting and on Boarding}

This component includes "competency based" recruiting for nurses to enhance the effectiveness and efficiency of the human resource.

\section{Performance Management and Performance}

This component encompasses ways to recognize nurses for their contributions in health care delivery. It includes measures to hold nurses accountable for their actions, but at the same time provides positive remarks and rewards for their efforts in providing quality patient care and assures them that nurses are not alone but along with the management support the system is based on team work.

\section{Critical Skills Gap Analysis and Training}

This component includes performing regular surveys to identify knowledge and competency gaps within nurses and strategizing ways to fill these gaps through trainings and awareness sessions. It also covers provision of opportunities for higher learning to nurses that are relevant, flexible, convenient, and timely.

\section{Compensation and Benefits}

This component of talent management covers provision of fair salary and other benefits, like medical coverage for self and family, earn leaves, study leaves and regular increments and performance bonuses as per organizations' policy. 


\section{Succession Planning}

This component explains the development of managers and leaders to provide transformational leadership that has positive impact on nurses' retention. It also covers providing opportunities to the high performers to become successors to key positions throughout the organization.

\section{Effective Exit Interviews}

This component allows management to identify reasons for nurses to discontinue their services. These interviews must be a part of the parting process. The interview shall not only focus the reasons of leaving but also the strengths and areas of improvement of the organization and constructive feedback as an opportunity to develop further.

The effective use of the above mentioned talent management practices will become increasingly critical to organization survival as the nursing shortage continues to worsen over time.

\section{Conclusions}

Shortage of health human resource particularly nurses is been an established area of concern for many health care organizations in both the developed as well as the developing countries. Hospital and nursing management are constantly showing their efforts to overcome this shortage but there are several prevailing factors which make this issue unavoidable for so long. With prevailing security situation, high cost impact of retention, sponsorship and escalating overseas demand, nurses' turnover and their shortage will remain a constant challenge in developing countries. Also the future hospital growth has made it inevitable to acquire nursing human resource from outside their city and country to meet the desired nurse patient ratio. Identifying and acknowledging the factors affecting nurses' retention and applying effective and timely strategies may help health care organizations to make progressive improvement in nurses' retention which in turn will show its impact in terms of positive patients and nurses outcome.

\section{References}

Buchan, J. \& Calman, L. (2004). The global Shortage of Registered Nurses: An Overview of Issues and Actions. ICN, Geneva. 
Business Recorder (2011). Pakistan Faces Shortage of Qualified Nurses, http://www.brecorder.com/pakistan/general-news/14073-pakistan-faces-shortageof-qualified-nurses.html

Castillo-Laborde, C. (2011). Human Resources for Health and Burden of Disease: An Econometric Approach. Human Resources for Health, vol.9:4.

Chen, L., Evans, T., Anand, S., Boufford, J.I., Brown, H., Chowdhury, M., Cueto, M. et al. (2004). Human Resources for Health: Overcoming the Crisis. The Lancet364 (9449), 1984-1990.

Clarin, O.A. (2007). Strategies to Overcome Barriers to Effect Nurse Practitioner and Physician Collaboration. The Journal of Nurse Practitioner, vol.3:8, pp.538-548.

Dow, S. (2003) Boosting the Ranks. Sydney Morning Herald, July 10, p.4

Gupta, N. \& Dal Poz, M.R. (2009) Assessment of Human Resources for Health Using Cross-National Comparison of Facility Surveys in Six Countries. Human Resource Health, vol.7:22.

Hunt, S.T. (2009). Nursing Turnover: Costs, Causes, and Solutions, http://www.uexcel.com/ resources/articles/NursingTurnover.pdf.

Jaffer, S. (2003). Job Satisfaction and Nurses Intend to Stay in a Private University Hospital in Karachi Pakistan. MScN Thesis.

Khowaja, K., Merchant, R.J. and Hirani, D. (2005) Registered Nurse's Perception of Work Satisfaction at a Tertiary Care University Hospital. Journal of Nursing Management, vol.131, pp.32-39.

Khuwaja, H. (2013). Nursing Shortage in Pakistan - Human Resource Management in Health Systems, http://blogs.jpmsonline.com/2013/08/23/nursing-shortage-inpakistan-human-resource-management-in-health-systems/

Lalani, N.S. (2005). The Process of Role Transition from Student to Staff among the Nurses of a University Teaching Hospital Karachi Pakistan. MScN thesis.

Manojlovich, M. \& Laschinger, H.K.S. (2008). Application of the Nursing Work Life Model to the ICU Setting. Critical care nursing clinics of North America, vol.20:4, pp.481-487. 
Mrayyan, M.T. (2008). Hospital Organizational Climates and Nurses' Intent to Stay: Differences between Units and Wards. Contemp Nurse. vol.27:2, pp.223-36

Rhay-Hung W., Ching-Yuan H., Wen-Chen T., Li-Yu C., Syr-En L. \& Mei-Ying L. (2010). Exploring the Impact of Mentoring Functions on Job Satisfaction and Organizational Commitment of New Staff Nurses. BMC Health Services Research.10:240 doi:10.1186/1472-6963-10-240.

Sliby, J. (2002). Nurse Shortage Plagues Leads to Health Care Industry Crisis. Boston Business Journal, July 15. http://boston.bizjournals.com/boston/stories/2002/07/15/ focus8.html.

Steven, T. H. (2009). Nursing Turnover: Costs, Causes \& Solutions. Success Factors Healthcare,http://www.nmlegis.gov/lcs/handouts/LHHS\%20081312\%20NursingT urnover.pdf.

Talent Management Strategies Research Report (2012). http://www.thebuildingfuturesgroup. com/wp-content/uploads/2014/03/Talent ManagementStrategiesReportOct12.pdf

The Philippine Star (2015). State of Phl Nurses Today, June 8, 2015 http://www.philstar.com/letters-editor/2015/06/08/1463396/state-phl-nursestoday

Van den Heede, K., Florquin, M., Bruyneel, L., Aiken, L., Diya, L., Lesaffre, E. \& Sermeus, W. (2013). Effective Strategies for Nurse Retention in Acute Hospitals: A Mixed Method Study. International Journal of Nursing Studies, vol.50:2, pp.185-194.

Verhaeghe, VeVlerick, Backer, Maele \& Gemmel (2008). The Relationship between Nursing Leadership and Nurses Job Satisfaction. Journal of Nursing Management, vol.16:5, pp.508-518.

World Health Organization. (2006). The World Health Report: 2006: Working Together for Health. http://www.bf.umich.edu/docs/KeyReferenceArticles.pdf Josh Bersin 
Figure 1: A framework for nurses' retention

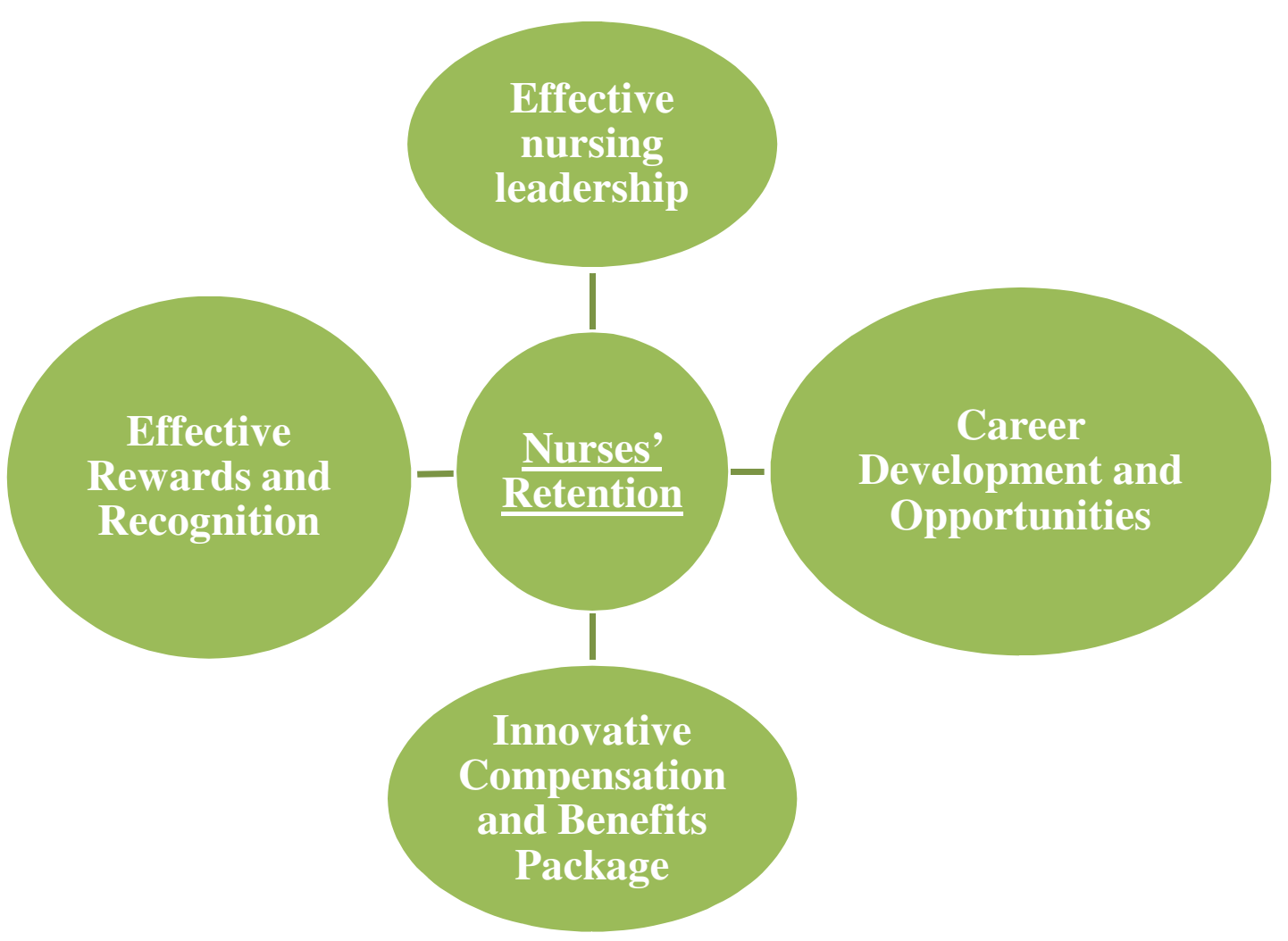


Figure 2: A nursing work life model (Manojlovich, \& Laschinger 2008)

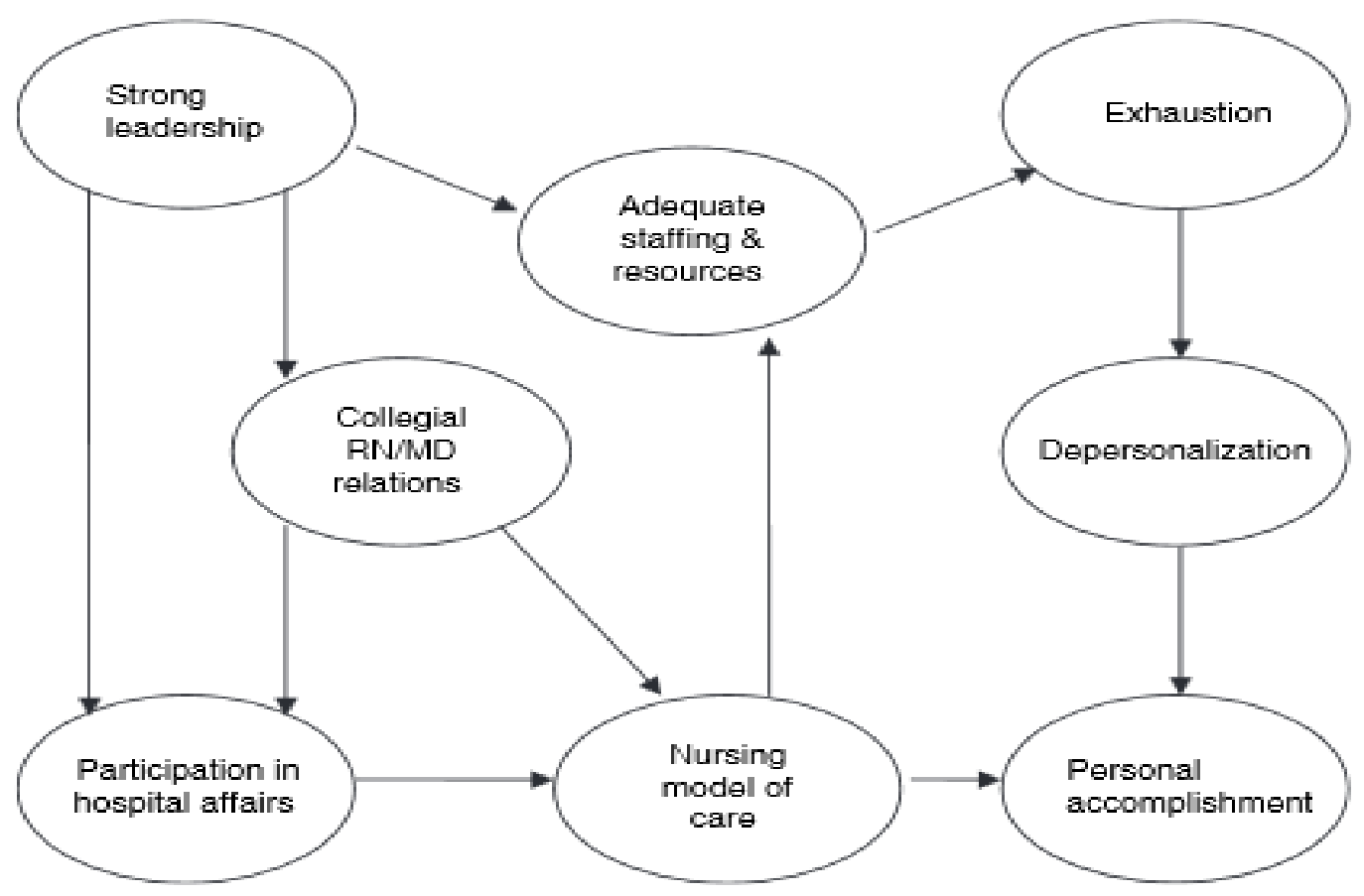

Dr. Rozina Karamaliani is Professor in the School of Nursing and Midwifery and Community Health Sciences, Aga Khan University, Karachi Pakistan.

Shirin Rahim is Instructor in the School of Nursing and Midwifery, Aga Khan University Karachi Pakistan.

Syed Aamir Hameed is an Assistant Professor in the Department of International Relations, University of Karachi, Pakistan 